Egyptian Veterinary Medical Society of Parasitology Journal

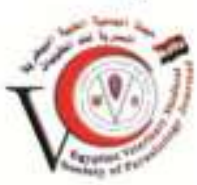

\title{
Original Article \\ First finding of antibodies to Encephalitozoon cuniculi in raised chickens in Egypt
}

Abu-Akkada
;Ashmawy K and EL
shanat S.
Department of
Parasitology, Faculty of
Veterinary Medicine,
Alexandria University
Abis, Alexandria, Egypt
Post Code: 21944
*Author of correspondence:
Somaia Saif Abu-Akkada
Professor of Parasitology
Head of Department of Parasitology
Acting Vice dean of Postgraduates
and researches affairs.
Faculty of Veterinary Medicine
Alexandria University
Egypt
E.mail:
somaia_abuakkada@ yahoo.com
Tel. +2 0452960306
Fax: +2 0452960450

\begin{abstract}
:
In the present study, the presence of antibodies against Encephalitozoon cuniculi in chickens of different breeds was investigated by the method of enzyme linked immunosorbent assay (ELISA). A total number of 88 serum samples were collected randomly from chickens raised in houses and commercial farms in different locations of Behera province, Egypt. The breeds sampled included Egyptian native breed (Baladi) chickens $(n=35)$, commercial egg-laying (Hy-line) breed $(n=40)$ and commercial broiler Sasso breed $(n=13)$. The age of the tested birds ranged from one month up to 20 months. Antibodies against E. cuniculi were detected in $13 / 88(14.77 \%)$ of sera examined. E.cuniculi antibodies were detected only in the sera of egg-laying chickens. Results of this study indicate that chickens are exposed to E.cuniculi infection in Egypt. These results are of epidemiological relevance and public health importance; as the presence of E.cuniculi in raised chickens indicates a risk of infection to humans, mainly chicken breeders. Therefore, routine screening examinations of large-scale breeding of chickens are advised considering the zoonotic potential of these parasites.
\end{abstract}

Key words: Encephalitozoon cuniculi ; Chicken, ELISA, Microsporidia

\section{Introduction:}

Microsporidia are a highly expanded and specialized group of unicellular intracytoplasmic protozoa that are found in wide variety of animal species. 150 genera of microsporidian parasites consisting about 1200 species have been reported until now. (Keeling and Fast, 2002). Microsporidian parasites are considered one of opportunistic pathogen especially in immunocompromised host such as patient infected with HIV, young age and aging host as well as patient who were subjected to organ transplantation operation, travellers and contact lens wearers (Didier, 2005). They are cosmopolitan parasites in addition they produce a resistant spores that can survive in surrounding environment and still infective for fairly long time. So, such characteristic feature of these parasites aids in recognition of suspected source of infections 
consequently helping in setting up a strategy of prevention and control (Kasickova et al., 2009). Several studies have been recruited to propose how the birds take apart in spreading of infective spore of microsporidia in the environment such as (Reetz, 1993 and 1999; Tocidlowski et al., 1997; Reetz et al., 2002; Snowden and Phalen, 2004; Haro et al., 2005; Lobo et al., 2006; SlodkowiczKowalska et al., 2006; Graczyk et al., 2007; Kas ic'kova' et al., 2007; Bart et al., 2008 and Muller et al. 2008).

Encephalitozoon cuniculi is
classified under the phylum of
Microspora (Sprague et al., 1992) and is considered one of among single cell eukaryote pathogen as well. Diagnosis of $E$. cuniculi is mainly depending on the serological approach, this is because the nature of its infection which is usually symptomless (Halanova et al., 1999). Many trials have been performed to identify the existence of antibodies of E. cuniculi in response to its antigens such as in 1972 a study was done by Cox et al., to identify antibodies in rabbits in addition, (Stewart et al., 1979) in dog. In the same context Gannon, (1980) diagnosed the E. cuniculi antibodies in mice. Alongside, Stewart et al., (1981) found the parasites antibodies in man while as, Singh et al., (1982) diagnosed the disease in sheep, as well as (Waller et al., 1983) tried to detect antibodies of E. cuniculi in goats, pig and horses. A recent study by AbuAkkada et al., (2015) has also confirmed the presence of E.cuniculi in different animal hosts in Egypt. But up till now a little is known about E.cunciuli in birds. Only three species of birds have been fallen under attack of E. cuniculi infection until now, in chronological order, chicken, cockateel (Nymphicus hollandicus) and pigeons
(Reetz, 1993, 1999; Kasickova et al., 2007; Bart et al., 2008) respectively.

The zoonotic relationship of microsporidian parasites between birds and human still mysterious and it was not confirmed up till now, nonetheless, some cases of ocular microsporidiosis were recorded in persons who were in close interaction with pet birds (Friedberg et al., 1990 and Yee et al., 1991). While as (Haro et al., (2005); Lobo et al. (2006) and Bart et al. (2008)) proposed that the microsporidia protozoans can be transmitted from birds to human without any borders. Furthermore, the dealing and management of exotic birds is probably a suspected source of infection (Kasickova et al., 2009).

Few data are available on the prevalence of $E$. cuniculi infection in domestic chickens and the numbers of researches have been performed to study the birds in contact with human are very limited so, we decided to investigate the presence of E.cuniculi in chickens (Gallus gallus) intended for human consumption. The basic target of the current study was to identify antibodies against E.cuniculi in house and commercially-raised chickens in Egypt.

\section{Materials and methods \\ Collection of samples}

A total of 88 serum samples were collected randomly from different locations in Behera province, Egypt. The breeds sampled included Baladi breed chickens $(n=35)$, commercial layer breed chickens $(n=40)$ and commercial broiler Sasso breed chickens $(n=13)$. The age of the tested birds ranged from one month up to 20 months (Sasso breed, 1.5 months, Baladi breed; 4-6 months and egglaying breed , 6- 20 months). Samples from Baladi chickens were collected from houses and those of commercially raised chickens were obtained from 
breeder farms. Blood samples were collected and sera were separated by centrifugation and stored at $-20{ }^{\circ} \mathrm{C}$ until use. All sera samples were analyzed by ELISA.

\section{E. cuniculi spores}

Spores of E. cuniculi (strain ATCC 50503) were generous provided by Dr. Esther van de Ven, QM Diagnostics (231QM), Nijmegen, Netherlands and used as an antigen in ELISA test.

\section{Manipulation of $E$. cuniculi spores and preparation of antigen}

(Akerstedt, 2002)

Firstly, the spores of $E$. cuniculi were frozen and thawed for three successive time, then the spores were sonicated (30 min, $60 \mathrm{~W}$ ) in BRANSON sonicator. Secondly, the step of measuring of the protein content that found in the supernatant was done as described by Lowry et al. (1951). Finally, the product of soluble antigen was kept at $-20^{\circ} \mathrm{C}$ waiting for procedure.

\section{ELISA procedures}

Sera of chicken were examined by indirect ELISA as designated by Akerstedt (2002). Shortly, Coating of Polystyrene microliters plates (Immunoplate Maxisorb; Nunc, Roskilde, Denmark) with the soluble antigen at a concentration of $2 \mu \mathrm{g} / \mathrm{ml}$. Afterward, the plates were incubated overnight at $4^{\circ} \mathrm{C}$, then washed with $200 \mu \mathrm{l} \mathrm{PBS} /$ Tween 20, and then treated with the blocking solution (3\% bovine serum albumin (BSA) with $0.05 \%$ Tween 20). A total of $50 \mu \mathrm{l}$ each of diluted tested chicken serum, negative control sera, and positive control sera (1:10) were added to each well and then incubated at $37{ }^{\circ} \mathrm{C}$ for $1 \mathrm{~h}$. After incubation, the plates were washed three times with $200 \mu \mathrm{l} \mathrm{PBS} / 0.05 \%$ Tween 20. After washing, horseradish peroxidase (HRP) conjugated Goat anti-Chicken IgG (KOMABIOTECH) was diluted at 1:5000 in PBS-T and added to the plates $(100 \mu \mathrm{l} /$ well $)$. Lastly, the plates were washed three times with PBS/0.05\% Tween 20, and the enzyme activity of bound peroxidase was revealed by adding 100 $\mu 1$ of ortho-phenylenediamine substrate (OPD) (Laboratories Inc., San Diego, CA, USA) to each well. After incubation in darkness (45 $\mathrm{min}$ ), the enzymatic color reaction was stopped by adding $100 \mu \mathrm{l}$ of $1 \mathrm{M}$ phosphoric acid to each well, and the optical density was read at $490 \mathrm{~nm}$ using a microplate reader (Corona Electrical, Japan). Cutoff value was calculated according to John (2009); Cutoff=Mean of negatives $+(3 \times \mathrm{SD}$ of negatives).

\section{Results}

88 chicken sera were totally investigated for presence of antibodies triggered by natural infection with parasites. E. cuniculi antibodies were detected in $14.77 \%$ (13 out of 88) of the examined birds. Cut off value $>0.508$ were considered positive. Seropositive chickens were only restricted in those birds of the laying breed group (birds of the highest age). E. cuniculi antibodies were recorded in birds without clinical signs suggestive of encephalitozoonosis. Positive results were detected in samples from 2 localities, Abu-elamatameer and Shobrakeit at Behera province, Egypt.

\section{Discussion}

Microsporidiosis is a cosmopolitan disease that is relatively understudied in comparison to other groups of human pathogens; as a consequence, our knowledge of this group of pathogens is continually evolving (Johny and Whitman, 2008). Although the advances of diagnostic approaches and continuous improvement of molecular techniques, there are several quires about this parasite still needed to be answered, 
Such as the way in which the organism is transmitted and the sources of infection as well.

The current serological assay assured the presence of antibodies of E. cuniculi in $14.77 \%$ (13/88) of raised chickens in Egypt. However, Reetz et al., (2002) described E. bieneusi as a first record of microsporidiosis in chicken (Gallus gallus). Moreover, E.cuniculi was incriminated in infection of only three types of birds; firstly, it was detected in chicken (Reetz, 1993, 1999) then later in 2007 was discovered in a cockateel (Nymphicus hollandicus) by (Kas'ic 'kova' et al., finally, Bart et al.,) then in 2008 it was found it in pigeons.

Reetz (1993) diagnosed $E$. cuniculi in chickens using immunohistochemical methods. His results showed that E. cuniculi infections in chickens can cause multisymptomatic illness but may also be clinically inapparent. Moreover, Reetz (1999) examined 100 chicken embryos for naturally occurring infections by immunohistochemical methods. $\mathrm{He}$ found that E. cuniculi was detected in about $40 \%$ of the embryos. His investigations demonstrated that $E$. cuniculi may be transmitted naturally to the chicken egg. Further, the results suggested that E. cuniculi may be a cause of death in chicken embryos. He added that in most cases, however, $E$. cuniculi infections are inapparent in embryos. Such inapparent infections may be an important way of contamination of chicken production units with E. cuniculi. Bart et al., ( 2008) identified microsporidial DNA in the droppings of pigeons in the Netherlands and E.cuniculi was the third most common microsporidial species identified. While, Lallo et al., (2012) demonstrated that exotic birds and pigeons play a potential role in transmission of the Encephalitozoon and Enterocytozoon genera for humans living in urban areas, as $24.5 \%$ of birds investigated in this study were infected with these parasites.

Surprisingly, we did not detect $E$. cuniculi in Egyptian Baladi breed chickens however the method of rearing this type of chickens may predict their susceptibility to infection with E.cuniculi spores. Where they were reared in small area and managed by the family staff themselves in addition of using neither unreliable nor selected food stuff. The chickens range freely in the household compound and find much of their own food or spend a large proportion of their time scratching to expose hidden food (Lambert and Radwan, 2010) which may be contaminated with E.cuniculi spores. Absence of infection with E.cuniculi in this breed could be attributed to their resistance to infectious diseases as reported by Abu Elezz (1994). On the other hand, the only breed found to be infected with E.cuniculi in the present study was the commercial Egg-laying type breed. Although, there is a good management and biosecurity system for chickens' rearing (Sonaiya and Swan, 2004) but infection with E.cuniculi with a relatively high percentage $(14.77 \%)$ may be attributed to stress and reduced immunity caused by egg laying. Besides, battery cage confinement in which this type of breed is living does not allow birds to turn around or take part in any other natural behavior. Prolonged forced confinement increases the incidence of disease and injury.

It was found that chickens of old age (egg laying breed; > 1 year) was the age category infected while young birds (Baladi and commercial Sasso breeds) were negative to E.cuniculi infection. This might be returned to age-dependent exposure to the parasite and/or predisposition to 
infection (Wilson et al., 2007 and Wang et al., 2018). However, Black et al., (1997) observed severe outbreaks of encephalitozoonosis with high mortality in young chicks, whereas adult birds in the same aviary appeared unaffected. Other several reports stated that avian microsporidiosis leading to high morbidity and mortality observed shortly after birds were brought into a new environment (Canning and Lom, 1986; Suter et al., 1998; Tocidlowski et al,. 1997). These observations suggest that latent infections as observed with E. cuniculi in other animals also occur in adult birds and that the stress may reduce the degree of resistance to this infection (Mathis et al., 2005).

Since the spores of E.cuniculi are shed in the urine for numerous weeks (Cox and Gallichio, 1978) and they are highly resistant to environmental conditions and can survive several months in humid climates (Li et al., 2003). Therefore, the possibility of avian-avian, avianhuman and human-avian transmission of microsporidia in the environment must be more carefully considered.

Graczyk et al., (2007) reported that contact with pigeon droppings for 30 minutes, for instance, when cleaning the droppings, is sufficient time to admit $3.5 \times 10^{3}$ infectious microsporidial spores into the human body. Moreover, bearing in mind the close relationship between chickens and humans, since, the microsporidia spore can be inhaled or get access the body through direct connection with mucosa as well as through oral route (Haro et al., 2005).

It could be concluded that the detection of E. cuniculi in raised chickens in the present study may have a major epidemiological impact on chicken breeders because both commercial and home-raised chickens contribute to environmental pollution with E.cuniculi spores and may be potentially infectious to any person in direct contact with them, for instance to chicken fanciers or ornithologists. This should direct our attention for the need of monitoring program for tracking this parasite especially in intensive farm of egg-laying type. From different point of view chickens may be probable used as animal model for studying the biology of microsporidia and for propagation of their spores.

\section{References}

Abu-Akkada, S.S., Ashmawy, K.I. and Dweir, A.W. (2015). First detection of an ignored parasite, Encephalitozoon cuniculi, in different animal hosts in Egypt. Parasitol Res 114:843-850.

Abu Elezz, N.T. (1994). Immunological studies on Eimeria species in fowls. Ph D Thesis, Fac Vet Med, Cairo Univ, Egypt.

Akerstedt, J. (2002). An indirect ELISA for detection of Encephalitozoon cuniculi infection in farmed blue foxes (Alopex lagopus). Acta Vet Scand 43:211-220.

Bart, A, Wentink-Bonnema, E.M., Heddema, E.R., Buijs, J. and van Gool, T. (2008). Frequent occurrence of human-associated

microsporidia in fecal dropping of urban pigeons in Amsterdam. Appl Environ Microbiol 74: 70567058.

Black, S. S., Steinohrt, L. A., Bertucci, D. C., Rogers, L. B. and Didier, E. S. (1997). Encephalitozoon hellem in budgerigars (Melopsittacus undulatus). Veterinary pathology, 34(3), 189-198. 
Canning, E.U and Lom, J. (1986). The Microsporidia of Vertebrates. Academic Press, London Ltd, United Kingdom.

Cox, J. C., Walden, N. B., and Nairn, R. C. (1972). Presumptive Diagnosis of Nosema aniiaili in Rabbits by Immunofluorescence. Res vet sci, 13(6), 595-598.

Cox, J.C. and Gallichio, H.A. (1978). Serological and histological studies on adult rabbits with recent, naturally acquired encephalitozoonosis.

Res Vet Sci 24: 260-261.

Didier, E.S. (2005). Microsporidiosis: an emerging and opportunistic infection in humans and animals. Acta Trop 94: 61-76.

Friedberg, D.N., Stenson, S.M. , Orenstein, J.M., Tierno, P.M. and Charles, N.C. (1990). Microsporidial keratoconjunctivitis in acquired immunodeficiency syndrome. Arch Ophthalmol 108:504-508.

Gannon, J. (1980). A survey of Encephalitozoon cuniculi in laboratory animal colonies in the United Kingdom. Lab Anim 14: 91-94.

Graczyk, T.K., Sunderland, D., Rule, A.M., da Silva, AJ., Moura, I.N.S., Tamang, L., Girouard, A.S. and Matos, O. (2007). Urban feral pigeons (Columba livia) as a source for waterborne contamination with Enterocytozoon bieneusi spores. Appl Environ Microbiol 73: 4357-4358.

Halanova, M., Letkova,V., Macak, V., Stefkovic, M. and Halan, M. (1999). The first finding of antibodies to Encephalitozoon cuniculi in cows in Slovakia. Vet Parasitol 82:167-171.
Haro, M., Izquiero, F., Henriques-Gil, N., Andres, I., Alfonso, F., Fenoy, S. and del Aguila, C. (2005). First detection and genotyping of human-associated microsporidia in pigeons from urban parks. Appl Environ Microbiol 71: 3153-3157.

John, R.C. (2009). The ELISA guidebook, 2nd ed Series: methods in molecular biology, pp 516-566.

Johny, S. and Whitman, D.W. (2008). Effect of four antimicrobials against an Encephalitozoon sp. (Microsporidia) in a grasshopper host. Parasitol Int 57: 362367.

Kasickova, D., Sak, B., Kvac, M. and Ditrich, O.( 2007). Detection of Encephalitozoon cuniculi in a new host- (Nymphicus hollandicus) using molecular methods. Parasitol Res 101: 1685-1688.

Kasickova, D., Sak, B., Kvac, M. and Ditrich, O. (2009). Sources of potentially infectious human microsporidia: molecular

characterization of microsporidia isolates from exotic birds in the Czech Republic, prevalence study and importance of birds in epidemiology of the human microsporidial infections. Vet Parasitol 165: 125-130.

Keeling, P.J., Fast, N.M. (2002). Microsporidia: biology and evolution of highly reduced intracellular parasites. Ann Rev Microbiol 56: 93-116.

Lallo, M.A., Calabria, P. and Milanelo, L. (2012). Encephalitozoon and Enterocytozoon (microsporidia) spores in stool from pigeons and exotic birds, Microsporidian in birds. Vet Parasitol 190: 418-422. 
Lambert, V. and Radwan, H.(2010). Gender assessment of Avian Influenza in Egypt. Dev Tech System Inc.

Lobo, M.L., Xiao, L., Cama, V., Magalhaes, N., Antunes, F. and Matos, O. (2006). Identification of potentially human pathogenic Enterocytozoon bieneusi genotypes in various birds. Appl Environ

Microbiol 72(11): 7380-7382.

Lowry, O.H., Rosebrough, N.J., Farr, A.L. and Randall, R.J. (1951). Protein Measurement with the Folin Phenol Reagent. J Biol Chem 193:265275.

Li, X., Palmer, R., Trout, J.M. and Fayer, R. (2003). Infectivity of microsporidia microsporidia spores stored in water at environmental temperatures. J Parasitol 89:185-188.

Mathis, A., Weber, R. and Deplazes, P. (2005). Zoonotic potential of the microsporidia. Clin Microbiol Rev 18: 423-445.

Muller, M.G., Kinne, J., Schuster, R.K. and Walochnik, J. (2008). Outbreak of microsporidiosis caused by Enterocytozoon bieneusi in falcons. Vet Parasitol 152: 67-78.

Reetz, J. (1993). Naturally-acquired microsporidia (Encephalitozoon cuniculi) infections in hens. Tierarztl Prax 21: 429-435.

Reetz, J. (1999). Natural transmission of microsporidia (Encephalitozoon cuniculi) by way of the chicken 150. egg. Tierarztl Prax 22: 147-

Reetz, J., Rinder, H., Thomschke, A., Manke, H., Schwebs, M. and Bruderek, A. (2002). First detection of the microsporidium

Enterocytozoon bieneusi in nonmammalian hosts (chickens). Int $\mathbf{J}$ Parasitol 32:785-787.

Singh, M., Kane, G.J., Mackinlay, L., Quaki, I., Yap, E.H., Ho, B.C., Ho, L.C. and Lim, K.C. (1982). Detection of antibodies to Nosema cuniculi (Protozoa: Microsporidia) in human and animal sera by theindirect

fluorescent antibody technique. Southeast Asian J Trop Med Public Health 13:110 113.

Slodkowicz-Kowalska, A., Graczyk, T.K., Tamang, L., Jedrzejewski, S., Nowosad, A., Zduniak, P., Solarczyk, P., Girouard, A.S. and Majewska, A.C. (2006). Microsporidian species known to infect humans are present in aquatic birds: implications for transmission via water? Appl Environ Microbiol 72: 4540-4544.

Snowden, K. and Phalen, D.N. (2004). Encephalitozoon infection in birds. Sem Avian Exotic Pet Med 13: 94 99.

Sprague, V., Becnel, J.J. and Hazard, E.I. (1992). Taxonomy of phylum Microspora. Crit. Rev. Microbiol. 18, 285-395.

Sonaiya, E.B. and Swan, S.E.J.(2004). Small-scale poultry production, technical guide. FAO. Animal production and health, Rome.

Stewart, C.G., Botha, W.S. and van Dellen, A.F. (1979). The prevalence of Encephalitozoon antibodies in $\operatorname{dogs}$ and an evaluation of the indirect fluorescent antibody test. JS Afr Vet Assoc 50: 169-172.

Stewart, C.G., van Dellen, A.F. and Botha, W.S. (1981). Antibodies to a 
canine isolate of Encephalitozoon in various species. S Afr J Sci 17: 572.

Suter, C., Mathis, A., Hoop, R. and Deplazes, P. (1998). Encephalitozoon hellem infection in a yellow-streaked lory (Chalcopsitta scintillata) imported from Indonesia. Vet Rec 143: 694-695.

Tocidlowski, M.E., Cornish, T.E., Loomis, M.R. and Stoskopf, M.K. (1997). Mortality in captive wildcaught horned puffin chicks (Fratercula corniculata). J Zoo Wildl Med 28:298-306.

Waller, T., Uggla, A. and Bergquist, N.R. (1983). Encephalitozoonosis and toxoplasmosis diagnosed simultaneuously by a novel rapid test: the carbon immunoassay. In: Proc. 3rd Int. Symp on Veterinary Laboratory Diagnosis 1, Ames, Iowa, USA, pp. 171-178

Wang, S., Yao, Z., Li, L., Pan, Y., Li, P., Nan, X.,Xie,q. and Zhang, Z. (2018). Seroprevalence of Toxoplasma gondii and Encephalitozoon cuniculi among domestic rabbits in central China. Parasite, 25,9.

Wilson, K., Bjornstad, O.N., Dobson, A.P., Merler, S., Poglayen, G., Randolph, S.E., Read, A,F. and Skorping, A.(2007). Heterogeneities in macroparasite infections: patterns and processes. In: Hudson PJ, Rizzoli A, Grenfell BT, Heesterbeek H, Dobson AP (eds) The ecology of wildlife disease. Oxford University Press, New York, pp 6-44.
Yee, R.W., Tio, F.O., Martinez, J.A., Held, K.S. , Shadduck, A. J. and Didier, E.S. (1991). Resolution of microsporidial epithelial keratopathy in a patient with AIDS. Ophthalmol 98:196-201. 


\title{
الملخص العربي
}

\section{الاكتشاف الأول للأجسام المضادة لطفيل إنسيفاليتوزون كونيكولي في الاجاج في}

\author{
مصر \\ *سمية سيف أبوعقادة، كرم إمام عشماوى و شريف كمال الثناط \\ قسم الطفيليات - كلية الطب البيطرى - جامعة الاسكندرية \\ أبيس، الإسكندريه

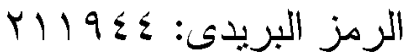 \\ somaia_abuakkada@yahoo.com:للمر اسلة:" \\ Tel. +2 0452960306 \\ Fax: +2 0452960450
}

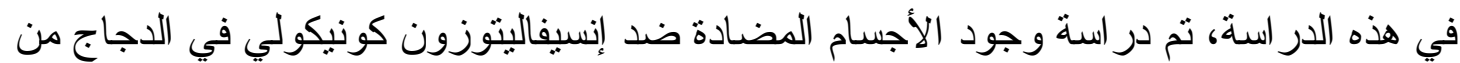

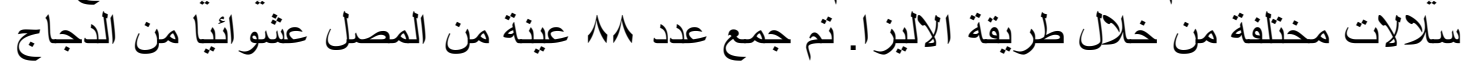

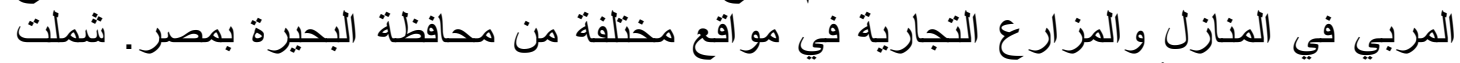

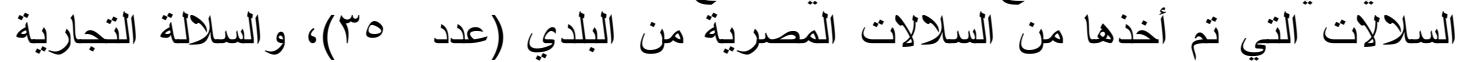

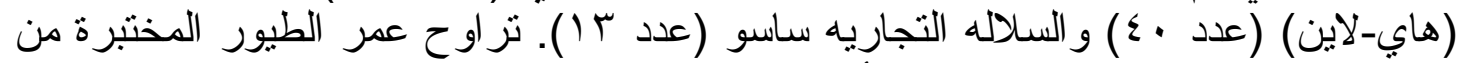

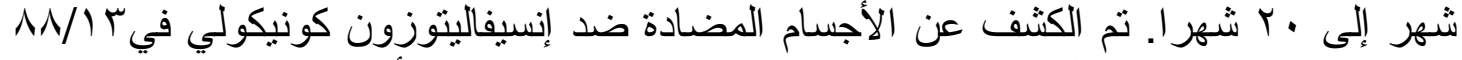
(\% ا \&.VV)

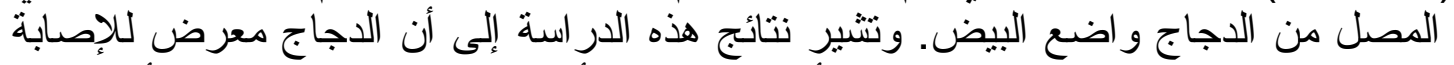

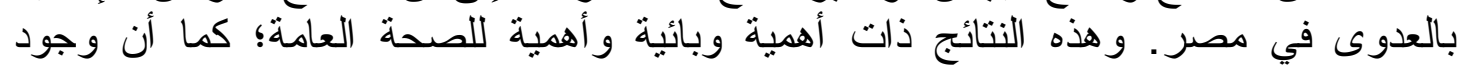

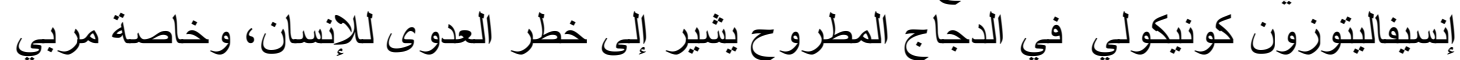

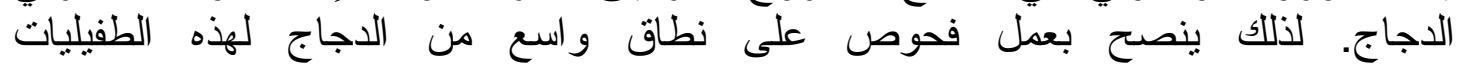

